\title{
Variation of Volatile Oil Contents and Constituents in Lesser Known Plant Species for Formulating Mosquito Repellents
}

\author{
Weerasinghe W.M.M. ${ }^{1 *}$, Subasinghe S.M.C.U.P. ${ }^{1}$, and Hettiarachchi D.S. ${ }^{2}$ \\ ${ }^{1}$ Department of Forestry and Environmental Science, University of Sri Jayewardenepura, Sri Lanka \\ ${ }^{2}$ Wescorp Group of Companies, Western Australia \\ *madhuweerasinghe13@gmail.com
}

\begin{abstract}
Volatile oils also known as essential oils are found in aromatic plants and contain volatile compounds that contribute to particular fragrances and flavours. Main uses of these volatile oils range from aroma therapy, food additives, cosmetics, natural medicines to insect repellents. Although there are common plants that produce volatile oils capable as mosquito repellents, certain plants are not known for this ability or under-utilised. Therefore, this research aimed at identifying lesser known volatile oil producing species and to formulate the plant products into safe and low cost insect repellents. An expert survey was first conducted by interviewing 7 subject experts and 13 local ayurvedic practitioners to identify the existing and potential volatile oil producing plant species which can be used as mosquito repellents. This survey identified 60 species and out of those 16 species (Ocimum tenuiflorum, Azadirachta indica, Acorus calamus, Atalantia ceylanica, Ocimum sanctum, Plectranthus amboinicus, Plectranthus zatarhendi, Vetiveria zizanioides, Acronychia pendunculata, Osmium gratissium, Aegle marmelos, Limonia acidissima, Murraya koenigii, Ricinus communis, Cinnamomum verum and Tagetes erecta) was selected after a weighted ranking system for further study. Hydro-distillation for 5 hours was used with $100 \mathrm{~g}$ of leaves for oil extraction for each species with three replicates. Particle size was kept at $1.5 \mathrm{~cm}$ for this purpose with 1:12 water ratio. Oil constituents were identified using GC-MS analysis. According to the results $C$. verum yielded the highest mean oil content $(0.0113 \pm 0.0024 \mathrm{ml} / \mathrm{g})$ followed by $A$. marmelos $(0.0095 \pm 0.0018 \mathrm{ml} / \mathrm{g})$. A ceylanica bears the highest number of constituents followed by M. koenigii and L. acidissima. However, the highest number of constituents which act as mosquito repellents showed by L. acidissima and C. verum as the present study. Those constituents are $\alpha$-Pinene, 3-Carene, Terpinolene, Caryophyllene oxide in C. verum and $\alpha$-Pinene, Limonene, Terpinolene and Caryophyllene oxide in L. acidissima.
\end{abstract}

Keywords: Volatile oil, Lesser known plants, Oil content, Oil constituents, Mosquito repellent

Acknowledgement: Centre for Forestry and Environment, University of Sri Jayewardenepura, Central Instrumentation facility of the Faculty of Applied Sciences, University of Sri Jayewardenepura and Sadaharitha Plantations Limited.

Proceedings of the $22^{\text {nd }}$ International Forestry and Environment Symposium 2017 of the Department of Forestry and Environmental Science, University of Sri Jayewardenepura, Sri Lanka 